\title{
The Unexpected in Primary Care: A Multicenter Study on the Emergence of Unvoiced Patient Agenda
}

\author{
Michael Peltenburg, MD, FAAPP ${ }^{1}$ \\ Joachim E. Fischer, MD, MSc ${ }^{2}$ \\ Ottomar Babrs, $\mathrm{PbD}^{3}$ \\ Sandra van Dulmen, $P b D^{4}$ \\ Atie van den Brink-Muinen, $P b D,{ }^{4}$ \\ for the investigators of the Euro- \\ Communication Study \\ 'Horten-Zentrum für praxisorientierte \\ Forschung und Wissenstransfer, Zurich, \\ Switzerland \\ ${ }^{2}$ Department of Behavioral Sciences, Swiss \\ Federal Institute of Technology, Zurich, \\ Switzerland \\ ${ }^{3}$ Georg-August-Universität, Zentrum \\ Psychologische Medizin, Göttingen, \\ Germany
}

${ }^{4}$ NIVEL (Netherlands Institute for Health Services Research), Utrecht, The Netherlands

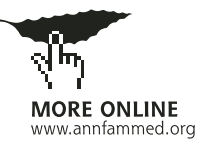

Conflicts of interest: none reported

\section{CORRESPONDING AUTHOR}

Michael Peltenburg, MD, FAAPP

Praxis Post

$\mathrm{CH}-8340$ Hinwil

Switzerland

Michael.Peltenburg@hin.ch

\begin{abstract}
PURPOSE Within the time constraints of a typical physician-patient encounter, the full patient agenda will rarely be voiced. Unexpectedly revealed issues that were neither on the patient's list of items for discussion nor anticipated by the physician constitute an emerging agenda. We aimed to quantify the occurrence rate of emerging agendas in primary care practices and to explain the variation between patients and practices.
\end{abstract}

METHODS This observational cross-sectional study involved 182 primary care practices in 9 European cultural regions. Consecutive primary care consultations were videotaped and rated. Patients completed preconsultation and postconsultation questionnaires assessing their expectations and perceived care. Emerging agenda, determined by using 11-item preconsultation and postconsultation questionnaires, was defined as care perceived by the patient to be in addition to expected care, after adjustment for cultural variations of patient expectations.

RESULTS For consultations involving 2,243 patients (mean age, 44.8 years, $58.4 \%$ women), every sixth (15.8\%) consultation revealed emerging psychosocial agenda. Biomedical agenda emerged in $14.5 \%$ of the consultations. Rates for unmet expectations were $13.6 \%$ and $10.3 \%$, respectively, for psychosocial and biomedical problems. Practices showed considerable heterogeneity of occurrence of emerging agenda (biomedical, median 13\%, range 0\%-67\%; psychosocial, median 14\%, range $0 \%-53 \%)$. After controlling for region and patient baseline characteristics, variables significantly related to emerging agenda were patient expectations and biomedical or psychosocial discourse content, but not consultation time or sex of the patient. A large proportion of the variance attributable to physicians remained concealed in a practice dummy variable (explaining up to $8 \%$ of the variance).

CONCLUSION Unexpected agenda emerges in every sixth to seventh consultation in outpatient primary care visits.

Ann Fam Med 2004;2:534-540. DOI: 10.1370/afm.241

\section{INTRODUCTION}

1

The core activity in primary care is consultation. ${ }^{1}$ Whether patients consult for cure, services, counseling, prevention, or care, a widely accepted model views the consultation as a dialogue involving elements of negotiation ${ }^{2}$ to create a common reality ${ }^{3,4}$ to which agenda setting is paramount. ${ }^{5}$

Within the time constraints of a typical physician-patient encounter, however, the full patient agenda will rarely be voiced. ${ }^{6}$ Eliciting the patient's agenda requires physicians to read cues. ${ }^{7}$ The following case illustrates this point: A 33-year-old overweight woman with poorly controlled diabetes visits her physician for her regular checkup. In scenario A, the physician rapidly proceeds to discussing the unsatisfactory levels of glycosylated hemoglobin. He provides advice on her lifestyle and insulin regimen, probably 
meeting her expectations. In scenario $B$, the physician takes her pensive mood upon receiving the latest levels of glycosylated hemoglobin as a cue for further exploration. During the consultation the theme of her concerns about a future pregnancy unexpectedly emerge. The physician offers support to find a common working strategy for achieving a low-risk pregnancy.

In both scenarios the patient would not have listed expectations concerning discussion of a future pregnancy. The agenda addressed in scenario B emerged unexpectedly to the physician and to the patient during the consultation. Hence, this patient's agenda does not fall into the dichotomization of met or unmet expectations. To fill this conceptual gap, we suggest the term emerging agenda. The example underscores the physician's professional role ${ }^{8}$ of clarifying health issues in a biopsychosocial context. ${ }^{9}$ Failure to do so has been related to adverse outcomes, patient dissatisfaction, or increased health care costs ${ }^{10-13}$ occurring in a relevant proportion of consultations. ${ }^{14}$

Emerging agenda is distinct from the related but more ambiguous concept of bidden agenda. This term was introduced to characterize the unrevealed patient's psychosocial background. ${ }^{15}$ More recently, hidden agenda referred to the patient's cues and the related physician's responses, ${ }_{1}^{16,17}$ or to the patient's expectations that were expressed in preconsultation interviews but remained unvoiced during the consultation. ${ }^{6}$

We explicitly define emerging agenda as concerns or issues not expected to be on the agenda by either the patient or the physician before the consultation. Appropriately responding to and dealing with an emerging agenda may characterize an affective consultation style. Physicians adopting an affective consultation style are more effective than colleagues adhering to formal consultations. ${ }^{18}$

Although the issue of unmet expectations has been extensively addressed, ${ }^{10,19-23}$ quantitative data regarding the emergence of unexpected themes in primary care are lacking. To address this shortcoming, we extended concepts of qualitative research ${ }^{6}$ to a multicenter study. Using process domains of cure and care, we compared patients' consultation expectations with perceived physicians' performance. We considered perceived physician performance that exceeded patients' expectations as indicating emerging agenda. The aims of the present study were to quantify the occurrence rate of emerging agenda in contemporary primary care and to elucidate factors for facilitating emerging agenda.

\section{METHODS}

The data were obtained from the Eurocommunication study, ${ }^{24,25}$ a cross-sectional study conducted in 9 European cultural regions on differences between European health care systems with respect to patient-physician communication. The study used multiple research methods, including extensive preconsultation and postconsultation questionnaires and video ratings of the consultations. The methods have been described in detail elsewhere. ${ }^{24,25}$

\section{Sample}

In total, 190 primary care physicians enrolled 3,658 patients into the study. Recruitment of physicians differed between countries. In the Netherlands and in the Flemish-speaking part of Belgium $(n=51)$, physicians were randomly selected from the national registry. In the United Kingdom, Germany, and Switzerland ( $\mathrm{n}=112$ ), physicians were recruited from ongoing research projects or by use of informal networks. In Spain $(n=27)$ physicians were employed in health maintenance organizations (HMOs). Except for holidays and the HMO practices, patients saw their personal physician on each visit.

Patient recruitment was as follows: on a preselected working day, consecutive patients were approached for enrollment into the study and informed consent. Patient refusal rates varied across practices and countries, ranging from $14 \%$ in Spain to $25 \%$ in Belgium. Patients were admitted until 20 patient consultations had been recorded. The first 3 consultations from each practice were excluded from the analysis. Also excluded were consultations with incomprehensible audio tracks or incomplete questionnaire data or video ratings, or when the patient and the physician left the room.

\section{Measures}

We hypothesized that the occurrence of emerging agenda may be related to the following categories of variables: (1) characteristics of the health care system, (2) the patient's or physician's sociodemographic variables, (3) the history of the patient-physician relationship, (4) the patient's self-assessment, (5) the physician's perception of the patient's actual problem, and (6) the content and process of the physician-patient communication.

Measures assessing these variables were obtained as follows: physicians completed a general questionnaire at the beginning of the study and a consultation-specific questionnaire at the end of each consultation; patients completed a questionnaire before the consultation and a brief questionnaire after the consultation. Independent observers rated the consultation videotapes.

\section{Determining Emerging Agenda}

Emerging agenda was defined as a positive difference between the preconsultation and postconsultation questionnaire scores, which occurred when patients perceived they had received more care than expected. 
perception of the patient and the consultation, and (6) the content and process variables of physician-patient communication. Parsimonious models were developed by backward removal of entered variables until Akaike's information criterion ${ }^{29,30}$ no longer improved. Briefly, Akaike's information criterion adds a penalty for each included variable. Minimizing Akaike's information criterion protects against overfitting of a model. In a last step, we entered a practice dummy variable to account for the variance attributable to practices, which was not captured by our measures. To illustrate the effect size of significant variables, adjusted odds ratios comparing the highest to the lowest quartile of the predictor were obtained from logistic regression analyses. The analytic software used was SAS Version 8.2 (SAS, Inc. Cary, NC, USA).

\section{RESULTS}

\section{Sample}

From the 3,658 patients providing informed consent, we obtained complete data sets for 2,243 consultations
(182 practices). According to International Classification of Primary Care diagnoses, physicians related $85 \%$ of patient morbidity to somatic illnesses. In most consultations $(94 \%)$ communication was the primary service offered. Patient characteristics between excluded and included consultations were similar, except for less consultation time for excluded patients (these data are displayed online only in a supplemental table, which can be found at: http://www.annfammed.org/cgi/ content/full/2/6/534/DC1). We found significant heterogeneity across cultural regions in a variety of aspects. For example, mean consultation time was 7.7 minutes in Spain and Eastern Germany and 21.2 minutes in the French-speaking part of Switzerland. Consultation times also differed between gatekeeping and fee-for-service practices ( 8.7 minutes vs 12.3 minutes, $P<.001)$.

\section{Preconsultation-Postconsultation Differences}

On the individual item level, most patients (range $68.4 \%-84.0 \%$ ) reported that their expectations were met (Table 1). The rate of reporting emerging agenda varied significantly across items (range $9.8 \%-23.7 \%, P<.001$,

\begin{tabular}{|c|c|c|c|}
\hline Explanatory Variable & $\begin{array}{c}\text { Explained Variance \% } \\
\left(\text { Partial } R^{2}\right)\end{array}$ & $\begin{array}{l}\text { Direction of } \\
\text { Association* }\end{array}$ & $\begin{array}{c}\text { Adjusted } \\
\text { Odds Ratio }(\mathrm{Cl})^{\dagger}\end{array}$ \\
\hline \multicolumn{4}{|l|}{ Biomedical factor } \\
\hline Full model & 42.3 & & \\
\hline Patient prior biomedical expectation & 27.4 & - & $0.02(0.01-0.04)$ \\
\hline Patient prior psychosocial expectations & .3 & - & $1.8(1.24-2.7)$ \\
\hline Biomedical discourse content & 1.2 & + & $2.2(1.5-3.1)$ \\
\hline Physician perceived psychosocial reason for encounter & 0.6 & - & $0.8(0.6-1.2)$ \\
\hline Region & 1.0 & Variable & NA \\
\hline Practice dummy variable nested within region & 7.9 & Highly variable & NA \\
\hline \multicolumn{4}{|l|}{ Psychosocial factor } \\
\hline Full model & 29.3 & & \\
\hline Patient prior psychosocial expectations & 13.2 & $+/-\neq$ & $3.3(2.3-4.7)^{\ddagger}$ \\
\hline Age & .1 & + & $2.0(1.3-3.1)$ \\
\hline Physical fitness & .2 & + & $1.3(0.9-1.9)$ \\
\hline Patient education & .1 & - & $0.7(0.5-1.1)$ \\
\hline Bothered by emotional problems & 1.6 & + & $1.9(1.3-2.8)$ \\
\hline Patient perceived psychosocial reason for consultation & .2 & + & $1.1(0.7-1.8)$ \\
\hline Physician perceives underlying psychosocial problem & .8 & + & $2.0(1.4-2.9)$ \\
\hline Affective or psychosocial discourse & .8 & + & $1.5(1.0-2.1)$ \\
\hline Proportion of consultation time physician is listening & .2 & + & $1.1(0.8-1.6)$ \\
\hline Region & .9 & Variable & NA \\
\hline Practice dummy variable nested within region & 7.4 & Highly variable & NA \\
\hline \multicolumn{4}{|c|}{$\begin{array}{l}\text { † Adjusted odds-ratio (OR): To illustrate the magnitude of the effects, the adjusted odds-ratio for emerging biomedical or psychosocial agenda are computed for a patient } \\
\text { scoring in the highest quartile on the respective scale compared with a patient scoring in the lowest quartile. Odds ratios are adjusted for all other variables that were sig- } \\
\text { nificant in the multivariable analysis of the continuous outcome measure. The model predicting an emerging psychosocial agenda performed well (area under the receiver } \\
\text { operating characteristic curve was } \alpha=0.76 \text { ) and the Hosmer-Lemeshow statistics showed an excellent fit with a } P=.77 \text {. The confidence interval (CI) is provided in paren- } \\
\text { thesis. Odds ratios for region and practice dummy variables are not shown (NA). }\end{array}$} \\
\hline \multicolumn{4}{|c|}{$\begin{array}{l}\text { F Comparison of the third quartile with the lowest quartile. Patients with very high psychosocial expectations were less likely to report emerging psychosocial agenda } \\
\text { (adjusted } \mathrm{OR}=0.66,95 \% \mathrm{Cl}, 0.45-0.97 \text { ), suggesting possible ceiling effects of the instrument. }\end{array}$} \\
\hline
\end{tabular}


Table 1), as did the proportion of patients reporting unmet expectations (range $3.9 \%-18 \%, P<.001$ ). Emerging agenda occurred most often regarding help for anxiety. According to our categorical definition, about every sixth to seventh patient reported emerging agenda in biomedical or psychosocial care. Patients reported unmet expectations most frequently regarding explanation of severity, prognosis, and test results (Table 1).

Regression analyses on the continuous outcome variable (degree of emerging agenda) revealed models explaining $42.3 \%$ of the variance in the biomedical difference factor $\left(F_{185 / 2058}=7.87, P<.001\right)$, and $29.3 \%$ of the variance in the psychosocial difference factor $\left(\mathrm{F}_{200 / 2042}=4.06, \mathrm{P}<.001\right)$. The most important determinants for emerging agenda were patient expectations ( $R^{2}=27.4 \%$ for the biomedical, and $R^{2}=13.2 \%$ for the psychosocial factor). Further significant variables are listed in Table 2.

Although multiple physician and consultationrelated variables were considered, they accounted for $19 \%$ only of the physician-attributable variance in the biomedical factor. The remainder eluded explanation and remained concealed in the practice dummy variable (Table 2). As to emergence of psychosocial themes, explanatory variables accounted for $20 \%$ of the physician-attributable variance. Post hoc analysis showed that physicians were more likely to exceed psychosocial care expectations if they perceived an underlying psychosocial problem, allowed the patient more relative speaking time, and engaged in psychosocial or affective discourse.

\section{Differences Across Practices or Health Context}

The rate of patients reporting emerging themes differed considerably across practices. For biomedical issues the range extended from $0 \%$ to $67 \%$ (interquartile range [IQR] 0\%-23\%); for psychosocial issues the range was $0 \%$ to $50 \%$ (IQR $7.1 \%-23 \%$ ). Whereas health care systems of regions varied considerably, regions accounted for less than $4 \%$ of the observed variability. Patients attending fee-for-service practices $(\mathrm{n}=101)$ reported results similar to those of patients seeing gatekeeping physicians $(\mathrm{n}=81)$ for the biomedical factor (standardized difference $[\mathrm{d}]=-.1,95 \% \mathrm{CI},-.24-.037, P=.15)$. After considering consultation time and other covariates, however, fee-for-service physicians facilitated the emergence of psychosocial themes more often than gatekeepers $(\mathrm{d}=.26,95 \% \mathrm{CI}, .17-.36, P<.001)$.

\section{Consultation Time and Sex of Patient and Physician}

Although yielding significant univariate associations (data not shown), several a priori hypothesized variables, including duration of consultation, were no longer retained in the final models once the number of psychosocial or affective utterances were considered. This finding also was true when number of utterances per unit of time were considered instead of absolute number of psychosocial or affective utterances. The final models also failed to retain patient or physician sex as significant. Post hoc analysis showed that the sex of the patient and physician exerted its effect by modifying patients' expectations and the discourse variables included in the model. For example, men seeing female physicians had fewer psychosocial expectations than did men consulting male physicians $(P<.001)$.

\section{DISCUSSION}

In this study across 9 European cultural regions, involving 2,243 patients from 182 practices, we assessed the extent to which patients reported having received more care than expected, which served as a working definition for emerging agenda. Unexpected biomedical and psychosocial agenda emerged during about every sixth to seventh consultation. Although we inquired whether physicians provided distinct domains of care as opposed to whether physicians performed specific medical tasks, we observed a rate of unmet expectations (12.5\%) similar to that found in a recent study $(11.6 \%) .{ }^{14}$

How do our findings translate into everyday practice? If a primary care physician sees 30 patients per day, unvoiced biomedical themes or psychosocial issues emerge about 5 times daily. These rates varied considerably among physicians, however. In practices within the lowest quartile of rates, unexpected biomedical or psychosocial agenda emerged less than once daily, whereas other physicians facilitated emerging agenda about 8 times more often.

Considering the large array of variables included in our models and given the heterogeneity across physicians, it was surprising how little of the variance attributable to physicians could be explained. Much of the art of facilitating emerging agenda, therefore, remains elusive and could not be captured by our method of consultation - by video rating or by questionnaires.

Our study also provided some unanticipated insights on variables unrelated to facilitating emerging agenda. Within the constraints of a given health care system or cultural region, and once discourse variables are considered, the absolute consultation duration was no longer related to emerging agenda or unmet expectations. The data suggest a dominance of the ability to recognize underlying psychosocial issues and to provide specific communication features during the time spent with the patient. Key variables found by our analysis were the proportion of time spent listening, the time spent on building emotional rapport, and 
the time devoted to medical explanations. Our findings underscore the notion that part of the skill of being a successful physician is making the most of available time in complex situations. ${ }^{31} \mathrm{~A}$ second surprising finding was that emerging agenda did not relate to sex of the patient or physician once patient expectations and the communication style were considered. Apparently these variables capture most of the effect attributed to gender found in the unadjusted analysis.

Several caveats of our study require consideration. First, our calculations are based on the assumption that differences between preconsultation and postconsultation questionnaire item scores allow inferences of emerging agenda or unmet expectations. At present, we consider this definition a first reasonable attempt to obtain a proxy for emerging agenda in the context of a quantitative study. Second, the questionnaire contained a ceiling effect whereby patients with high expectations were less likely to report having received more care than expected. This effect reduced the possibility to detect emerging agenda in this subgroup of patients. Third, inquiring about expectations before the consultation may have introduced a bias by encouraging patients to become more conscious of their concerns. This redefining of the patient agenda may also have reduced the chance of detecting differences. Fourth, we cannot exclude a reporting bias or pleasing-theinvestigator bias. We consider the possible distortion of results due to this bias as minimal given not only the marginally positive means on both continuous outcome factors but also the similar occurrence rate of unmet expectations reported in an independent contemporary study. ${ }^{14}$ Fifth, 39\% of the patients were excluded from being fully videotaped. These patients had a slightly higher proportion of visits $(+3.8 \%)$ for psychosocial reasons, which may have impeded our ability to show associations of explanatory variables with the psychosocial factor score. Finally, the nonrandom sampling of practices in some countries prevents inferences about the specific cultural regions. The observed differences attributable to region were small, however, suggesting that our core findings remain robust across a considerable heterogeneity of cultural and health care settings. Because the study focused on the patient as the arbiter of perceived care, ${ }^{32}$ it did not provide an objective comparison of physicians' delivery of care.

Bearing these limitations in mind, our data suggest the existence of unvoiced latent agenda in a considerable proportion of patients consulting primary care physicians. The macrolevel health care context does not appear to explain differences between physicians in meeting the patients' need to know and understand and to be known and understood. Throughout all the regions and health care systems, we found physicians who facilitated the emergence of unvoiced themes in a large proportion of their patients, and physicians who, while acting within the same constraints, failed to do so. Our data underscore the practical relevance of appropriate agenda setting as put forward by the

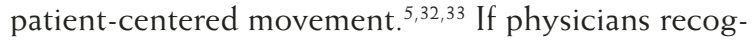
nize cues pointing to these latent issues, and if they aid the voicing of these issues, the emerging agenda may foster the patient's sense of empowerment and satisfaction. A first step is to acknowledge that good communication skills do not come naturally; they require training and practice, just as other medical skills do.

To read or post commentaries in response to this article, see it online at http://www.annfammed.org/cgi/content/full/2/6/534.

Key words: Primary health care; patient acceptance of health care; patient satisfaction; physician-patient relations; communication; patientcentered care

Submitted October 9, 2003; submitted, revised, January 25, 2004; accepted February 17, 2004.

Funding support: This study was supported by the BIOMED-II research program of the European Union Grant No. BMH4-CT96-1515, and the Swiss National Science Foundation Grant No. 32-49306.96.

Study investigators: A van den Brink-Muinen, PFM Verhaak, JM Bensing, NIVEL, Utrecht, The Netherlands; O Bahrs, University of Göttingen, Germany; M Deveugele, University of Ghent, Belgium; L Gask, N Mead, University of Manchester, United Kingdom; F Leiva-Fernandes, A Perez, Unitad Docente de Medicina Familiar y Comunitaria, Servicio Andaluz de Salud, Malaga, Spain; L Oppizzi, M Peltenburg, Arbeitsgemeinschaft "Arzt-Patienten Kommunikation," Switzerland.

\section{References}

1. Howie JG, Heaney DJ, Maxwell M, Walker JJ, Freeman GK, Rai H. Quality at general practice consultations: cross sectional survey. BMJ. 1999; 319:738-743.

2. Lazare A. The interview as a clinical negotiation. In: Lipkin ML, ed. The Medical Interview. New York, NY: Springer Verlag; 1995:50-62.

3. Anderson TW, Helm DT. The physician-patient encounter: a process of reality negotiations. In: Jaco EG, ed. Patients, Physicians, and IIIness: A Sourcebook in Behavioral Science and Health. New York, NY: Free Press; 1979:259-271.

4. Schwartz CG, Kahne MJ. Medical help as negotiated achievement. Psychiatry. 1983;46:333-349.

5. Levenstein JH, McCracken E, McWhinney IR, Stewart MA, Brown JB. The patient-centred clinical method. 1. A model for the doctorpatient interaction in family medicine. Fam Pract.1986;3:24-30.

6. Barry CA, Bradley CP, Britten N, Stevenson FA, Barber N. Patient's unvoiced agendas in general practice consultations: qualitative study. BMJ. 2000;320:1246-1250.

7. Lang F, Floyd MR, Beine KL. Clues to patients' explanations and concerns about their illnesses. A call for active listening. Arch Fam Med. 2000;9:222-227.

8. Turner JA, Deyo RA, Loeser JD, Von Korff M, Fordyce WE. The importance of placebo effects in pain treatment and research. JAMA. 1994; 271:1609-1614. 
9. Engel GL. The need for a new medical model: a challenge for biomedicine. Science. 1977;196:129-136.

10. Kravitz RL, Callahan EJ, Azari R, Antonius D, Lewis CE. Assessing patients' expectations in ambulatory medical practice. Does the measurement approach make a difference? J Gen Intern Med. 1997; 12:67-72.

11. Kravitz RL, Callahan EJ. Patients' perceptions of omitted examinations and tests: a qualitative analysis. J Gen Intern Med. 2000;15:38-45.

12. Jackson JL, Kroenke K. The effect of unmet expectations among adults presenting with physical symptoms. Ann Intern Med. 2001;134:889-897

13. Kravitz RL. Measuring patients' expectations and requests. Ann Intern Med. 2001;134:881-888.

14. Bell RA, Kravitz RL, Thom D, Krupat E, Azari R. Unmet expectations for care and the patient-physician relationship. J Gen Intern Med. 2002; 17:817-824.

15. Balint M. The Doctor, His Patient and the Illness. 1st ed. London: Pitman; 1957.

16. Del Piccolo L, Benpensanti MG, Bonini P, et al. The Verona Medical Interview Classification System/Patient (VR-MICS/P): the tool and its reliability. Epidemiol Psichiatr Soc. 1999;8:56-67.

17. De Valck C, Bensing J, Bruynooghe RM, Hulsman RL, Kerssens JJ. Cue-responding in a simulated bad news situation: exploring a stress hypothesis. J Health Psychology. 2001;585-596.

18. Di Blasi Z, Harkness E, Ernst E, Georgiou A, Kleijnen J. Influence of context effects on health outcomes: a systematic review. Lancet. 2001;357:757-762

19. Williams S, Weinman J, Dale J, Newman S. Patient expectations: what do primary care patients want from the GP and how far does meeting expectations affect patient satisfaction? Fam Pract. 1995; 12:193-201.

20. Brody DS, Miller SM, Lerman CE, Smith DG, Lazaro CG, Blum MJ. The relationship between patients' satisfaction with their physicians and perceptions about interventions they desired and received. Med Care. 1989;27:1027-1035.
21. Kravitz RL, Cope DW, Bhrany V, Leake B. Internal medicine patients' expectations for care during office visits. J Gen Intern Med. 1994;9:75-81.

22. Kravitz RL, Callahan EJ, Paterniti D, Antonius D, Dunham M, Lewis CE. Prevalence and sources of patients' unmet expectations for care. Ann Intern Med. 1996;125:730-737.

23. Marple RL, Kroenke K, Lucey CR, Wilder J, Lucas CA. Concerns and expectations in patients presenting with physical complaints. Frequency, physician perceptions and actions, and 2-week outcome. Arch Intern Med. 1997; 157:1482-1488.

24. van den Brink-Muinen A, Verhaak PFM, Bensing JM. The Eurocommunication Study. Utrecht: NIVEL; 1999.

25. van den Brink-Muinen A, Verhaak PF, Bensing JM, et al. Doctorpatient communication in different European health care systems: relevance and performance from the patients' perspective. Patient Educ Couns. 2000;39:115-127.

26. Kravitz RL. Patients' expectations for medical care: an expanded formulation based on review of the literature. Med Care Res Rev. 1996;53:3-27.

27. Roter DL. The Roter method of interaction process analysis. unpublished . 1985. Department of Behavioral Sciences and Health Education, Johns Hopkins University.

28. Roter DL, Hall JA. Studies of doctor-patient interaction. Ann Rev Public Health. 1989;10:163-180.

29. Bozdogan H. Model selection and Akaike's information criterion: the general theory and its analytical extensions. Psychometrika. $1987 ; 52: 345-370$.

30. Akaiki H. Factor analysis and AIC. Psychometrika. 1987;52:317-332.

31. Freeman GK, Horder JP, Howie JGR, et al. Evolving general prac tice consultation in Britain: issues of length and context. BMJ. 2002;324:880-882

32. Epstein RM. The science of patient-centered care. J Fam Pract. 2000;49:805-807.

33. Stewart M, Brown JB, Donner A, et al. The impact of patient-centered care on outcomes. J Fam Pract. 2000;49:796-804. 